\title{
Identification of Tisp40 as an Essential Regulator of Renal Tubulointerstitial Fibrosis via TGF- $\beta /$ Smads Pathway
}

\author{
Cheng-cheng Xiao Jie Zhang Peng-cheng Luo Cong Qin Yang Du \\ Jin-zhuo Ning Hai-zhou Zheng \\ Department of Urology, Renmin Hospital of Wuhan University, Hubei, China
}

\section{Key Words}

Tisp40 • Ischemia-reperfusion • Renal tubulonterstitial fibrosis • TGF- $\beta$ • Smad

\begin{abstract}
Background: Tisp40, a transcription factor of the CREB/CREM family, is involved in cell proliferation, differentiation and other biological functions, but its role in renal tubulointerstitial fibrosis is unknown. Methods: In our study, we investigated the effects of Tisp40 on extracellular matrix (ECM) accumulation, epithelial-mesenchymal transition (EMT) and the underlying molecular mechanisms in transforming growth factor- $\beta$ (TGF$\beta$ )-stimulated TCMK-1 cells by quantitative real-time polymerase chain reaction ( $q P C R$ ), Western blot analysis and immunofluorescence in vitro, and further explored the role of Tisp40 on renal fibrosis induced by ischemia-reperfusion (I/R) by qPCR, Western blot analysis, hydroxyproline analysis, Masson trichrome staining and immunohistochemistry staining in vivo. Results: The data showed that Tisp40 was upregulated in a model of renal fibrosis induced by I/R injury (IRI). Upon IRI, Tisp40-deficient mice showed attenuated renal fibrosis compared with wild-type mice. Furthermore, the expression of $\alpha$-smooth muscle actin, E-cadherin, fibronectin, and collagen I was suppressed. Tisp40 overexpression aggravated ECM accumulation and EMT in the TGF- $\beta$-stimulated TCMK-1 cell line, whereas the opposite occurred in cells treated with small interfering RNA (siRNA) targeting Tisp40. Importantly, it is changes in the Smad pathway that attenuate renal fibrosis. Conclusion: These findings suggest that Tisp40 plays a critical role in the TGF- $\beta /$ Smads pathway involved in this process. Hence, Tisp40 could be a useful therapeutic target in the fight against renal tubulointerstitial fibrosis.
\end{abstract}

\section{Introduction}

Statistics suggest that the global incidence rate of chronic kidney disease (CKD) due to various causes is $8-16 \%$, and renal tubulointerstitial fibrosis is considered a common

\section{KARGER}




\section{Cellular Physiology Cell Physiol Biochem 2017;42:697-712 \begin{tabular}{l|l|l|l} 
DOI: 10.1159/000477887 & (c) 2017 The Author(s). Published by S. Karger AG, Basel
\end{tabular} \\ Xiao et al. Tisp40 in Renal Tubulointerstitial Fibrosis}

outcome of CKD [1,2]. Approximately $60 \%$ of patients who survive acute kidney injury (AKI) develop CKD [3]. Research shows that AKI accelerates the development of CKD, while patients with CKD have a higher probability of suffering from AKI [4, 5]. Ischemiareperfusion (I/R) injury (IRI), whose pathological changes are acute renal tubular apoptosis and necrosis, is a main cause of AKI. Epithelial-mesenchymal transition (EMT) is a determinant of renal tubulointerstitial fibrosis [6,7], which represents a loss of epithelial markers, including E-cadherin, and an increase in mesenchymal markers, such as alpha smooth muscle actin ( $\alpha$-SMA) [8-10]. In the process of renal tubulointerstitial fibrosis, tubular epithelial cells that encounter various injury stimuli undergo a dedifferentiation [11-13]. The short-term injured de-differentiated tubular epithelial cells can proliferate and re-differentiate to restore the structural and functional stability of nephrons [14]. However, under severe and repetitive stimulation, the de-differentiated tubular epithelial cells release profibrotic mediators that cause a transformation from tubulointerstitial cells, including fibroblasts and pericytes, to scar-producing cells, leading to the accumulation and deposition of extracellular matrix (ECM) $[10-13,15]$. Renal function can recover after ischemic injury, but the accumulation and deposition of ECM combined with the proliferation of fibroblasts leads to renal tubulointerstitial fibrosis, which progresses to CKD $[4,16]$. Evidence indicates that TGF- $\beta$ plays a key role and activates downstream Smad signaling in mediating the process of renal tubulointerstitial fibrosis [17-19].

Recently, Tisp40 and other endoplasmic reticulum (ER) membrane-bound bZIP domain-containing transcription factors, which have a transmembrane (TM), a transcription-activation, and a bZIP domain and share a region of high sequence homology with activating transcription factor 6 (ATF6), have been identified [20]. Mouse Tisp40 encodes Tisp $\alpha /$ Atce 1 and Tisp $40 \beta$, which differ in starting point, downstream or upstream of the first exon. In humans, Tisp40 is located in 1q21.3, encoding 395 amino acids [21]. As a transcription factor, Tisp40 can bind to a variety of response elements, such as CRE response element, NF-Kb response element and unfolded protein response element (UPRE), to initiate the transcription of multiple genes [20]. Tisp40 (also named CREB3L4, AIbZIP, or ATCE1) disruption activates caspase 12 via the endoplasmic reticulum stress protein $\mathrm{Grp78/BiP}$ and the membrane protein ribosomeassociated 4 (RAMP4), leading to the apoptosis of meiotic/postmeiotic germ cells and the aggregation and acetylation of sperm in epididymis [22]. In humans, Tisp40 is highly expressed in the prostate. Its expression level in prostate cancer tissue is higher than in normal tissue and epithelial tumor tissue, and androgens can induce the expression of Tisp40 in a dose-dependent manner in a prostate cancer cell line [21,23]. Compared with normal tissues, HCC tissues express more Tisp40 protein [24]. However, its role in the differentiation of renal tubular cells and renal tubulointerstitial fibrosis is unknown.

In this study, we demonstrate a novel role of Tisp 40 in renal tubulointerstitial fibrosis. We find that the loss of Tisp40 in the kidney prevents I/R-induced tubulointerstitial fibrosis by inhibiting ECM accumulation and EMT, and we further demonstrate that this inhibitory action is mediated by a reduction in Smad2/3 phosphorylation. These results show that in all probability, Tisp40 is a potential target gene for the treatment of renal tubulointerstitial fibrosis.

\section{Materials and Methods}

\section{Animals and Surgical Protocals}

All surgical procedures were conducted according to the Guide for the Care and Use of Laboratory Animals (1996) and approved by the Institutional Animal Care and Use Committee of Wuhan University. Male C57BL/6 mice (20-25g) were obtained from the Center of Experimental Animals in Wuhan University Medicine College (Hubei, China). Tisp40-knockout mice crossed into a C57BL/6 background were purchased from RIKEN BioResource Center (Stock NO. RBRC01942). The kidney 


\section{Cellular Physiology Cell Physiol Biochem 2017;42:697-712 \begin{tabular}{l|l|l|l|l} 
DOI: 10.1159/000477887 2017 The Author(s). Published by S. Karger AG, Basel & \\
\hline
\end{tabular} Published online: June 13, 2017 www.karger.com/cpb \\ Xiao et al.: Tisp40 in Renal Tubulointerstitial Fibrosis}

morphology and function is no appreciable defect in phenotypically normal Tisp40-/-mice. All mice caged in a standard temperature-controlled room with alternating 12-h light/dark cycles, free access to water and standard laboratory diet. The mice were randomly divided into 4 groups: (1) wild-type sham-operated; (2) wild-type renal I/R; (3) Tisp40-knockout sham-operated; (4) Tisp40-knockout renal I/R ( $\mathrm{n}=6$ per group).

At 10 weeks of age, Tisp40-knockout and wild-type C57BL/6 mice were abdominal anaesthetized with Phenobarbital Sodium $(60 \mathrm{mg} / \mathrm{Kg})$. After induction of anesthesia, the mice were placed abdomen on a heated table to keep a rectal temperature of $37-38^{\circ} \mathrm{C}$. The occurance of loss of righting reflex proved to desired depth of surgical anesthesia. A left flank subcostal incision was made approximately 1-1.5 cm, followed by careful dissection to remove the perihilar adipose tissue for the exposed blood vessels. Afterwards we use a microvascular clamp the blood vessels as little perihilar fat as possible for $30 \mathrm{~min}$. Then, a $0.5 \mathrm{~cm}$ lowered incision was made in the right, and the right kidney underwent an identical surgical procedure. If the induction of ischemia is successful, the appearance of kidney will change from red to dark purple within 1-2 minutes gradually. Layer sutured and incision closed with a suture, the postoperative animals were carefully transferred into an incubator which was set at a fixed temperature. Sham-operated mice (wild-type sham-operated+Tisp40-knockout shamoperated) underwent the same procedure without clamping of the renal blood vessels. At 10 weeks post operatively, the animals were sacrificed by pentobarbital sodium overdose. After removed under fully maintained anesthesia, the left kidneys were snap-frozen in liquid nitrogen and stored at $-80^{\circ} \mathrm{C}$ or fixed in 4\% paraformaldehyde for biochemical analysis and pathological evaluation.

\section{Hydroxyproline Analysis}

Samples of kidneys of wild-type sham-operated, wild-type renal I/R, Tisp40-knockout shamoperated and Tisp40-knockout renal I/R mice were hydrolyzed by $6 \mathrm{~mol} / \mathrm{L} \mathrm{HCl}$ at $110^{\circ} \mathrm{C}$ for $18 \mathrm{~h}$, and then centrifuged at 18,000 g for $2 \mathrm{~min}$, followed by frozen-drying. The content of hydroxyproline in each group was analyzed with a hydroxyproline analysis kit (Sigma-Aldrich).

\section{Masson Trichrome Staining}

Samples from paraffin-embedded tissues were prepared at $4 \mu \mathrm{m}$ thickness, stained with Masson's trichrome. Masson trichrome staining, a standard for visualizing fibrosis in tissue, provides tissue morphology, allowing evaluation of localization and severity of deposition of extracellular matrix.

\section{Immunohistochemistry Staining}

Kidney sections $(4-\mu \mathrm{m})$ were deparaffinized and then hydrated in graded ethanol followed by blocked with $3 \%$ hydrogen peroxide for $15 \mathrm{~min}$ at room temperature. The sections were then treated with $10 \%$ normal goat serum in Tris-buffered saline for $30 \mathrm{~min}$ at $37^{\circ} \mathrm{C}$. Subsequently, they were incubated overnight at $4^{\circ} \mathrm{C}$ with the following primary antibodies against Tisp40 (1:100; sc54800; Santa), alpha smooth muscle actin (1:100; ab5694; Abcam), E-cadherin $(1: 50 ; 610181$; BD Biosciences), collagen I (1:150; ab34710; Abcam), fibronectin (1:200; ab2413; Abcam), phosphor(p) Smad2/3 (D27F4; 1:100; Cell signaling technology) and Snail (1:300; ab180714; Abcam). Afterwards the sections were washed three times in PBS and incubated with horseradish peroxidase (HRP)conjugated anti-rabbit/mouse IgG secondary antibodies (Dako; Glostrup, Denmark.) for $10 \mathrm{~min}$ at $37^{\circ} \mathrm{C}$. A dark brown color reaction was developed with 3,3'-diaminobenzidine (Beyotime Institute of Biotechnology, Shanghai, China) in the presence of $3 \%$ hydrogen peroxide, and terminated by washing twice in distilled water. The percentage of area stained represents the ratio of the summed absolute areas of staining versus the total tissue.

\section{Cell culture and Treatment}

Renal tubular epithelial cell line TCMK-1/wildtype (TCMK-1/wt) (ATCC number CCL-139) were cultured in DMEM (GNM12800, Gino bio-medical technology Co., Ltd.) supplemented with 10\% fetal bovine serum (FBS; Gibco, Gaithersburg, MD, USA) and $1 \%$ penicillin- streptomycin at $37^{\circ} \mathrm{C}$ under a $95 \%$ air and 5\% CO2 condition. A total of $1.5 \times 106$ cells $/ \mathrm{ml}$ cells were transferred to 6 -well plates for group comparison study. After the cells which reached $70 \%$ confluence were provided a $12 \mathrm{~h}$ starvation, TGF- $\beta$ (Millipore, London, UK) was added into the medium at a final concentration of $10 \mathrm{ng} /$ $\mathrm{ml}$ for $2 \mathrm{hrs}$ or $24 \mathrm{hrs}$. 


\section{Cellular Physiology Cell Physiol Biochem 2017;42:697-712 \begin{tabular}{ll|l} 
DOI: 10.1159/000477887 & C 2017 The Author(s). Published by S. Karger AG, Basel
\end{tabular} Published online: June 13, $2017 \quad$ www.karger.com/cpb \\ Xiao et al.: Tisp40 in Renal Tubulointerstitial Fibrosis}

Total RNA isolation and quantitative real-time PCR

Total RNA of renal samples and TCMK-1 cells was extracted with TRIzol® Reagent (Invitrogen,15596026), according to the manufacturer's protocol. RNA underwent purification with DNase (Fermentas, EN0521), the purity of which was assessed by determining the absorbance ratio at A260/A280. Total RNA was reverse transcribed into cDNA using RevertAid Reverse Transcriptase (Fermentas, EP0442), dNTP (Fermentas, R0191) and RiboLock RNase Inhibitor (Fermentas, E00381). Quantitative real-time PCR (qPCR) was performed using KAPA SYBRR FAST qPCR Kit Master Mix(2X) ABI PrismTM (KAPA,KK4605) and Real-Time PCR Systems instrumentation and software(ABI stepone plus). Primer sequences for the renal samples were as follows: Tisp40 forward 5' - TACCTGAAGCCCCAACTACAAA-3', and reverse, 5'- GTGCCCTGCCACATGATAAA-3'; $\alpha$-SMA forward 5'-CGAAACCACCTATAACAGCATCA-3', and reverse, 5'-GCGTTCTGGAGGGGCAAT-3'; fibronectin forward, 5'-AGGCTGGATGATGGTGGACT-3', and reverse, 5' -CGGCTGAAGCACTTTGTAGAG-3'; collagen I forward, 5'-CCCCAGCCGCAAAGAGT-3' , and reverse, 5'-ATTGTGGCAGATACAGATCAAGC-3'; E-cadherin forward, 5'-TTCAAAGTGGCGACAGACGG-3', and reverse, 5'-GGGTACACGCTGGGAAACAT-3'; Snail forward, 5'-TCTGCACGACCTGTGGAAAG-3', and reverse, 5'-GCAGTGGGAGCAGGAGAATG-3'; TGF- $\beta$ forward, 5'-TAATGGTGGACCGCAACAAC-3', and reverse, 5'-CACTCAGGCGTATCAGTGGG-3'; (Invitrogen). Expression of all target genes was normalized to that of $\beta$-actin, which had the following primer sequences: Forward 5' - CTGAGAGGGAAATCGTGCGT-3' and reverse, 5' - CCACAGGATTCCATACCCAAGA-3' (Invitrogen). The relative mRNA expression levels were determined using the $2-\Delta \Delta$ Cq method [25].

\section{Western blotting}

Proteins from renal tissues or cultured TCMK-1 cells were extracted with RIPA Lysis Buffer (P0013B, Beyotime Institute of Biotechnology).The protein concentration was determined using a BCA protein assay kit (K763-KIT, Amresco).The protein $(50 \mu \mathrm{g})$ loaded in each lane was separated by sodium dodecyl sulfate-polyacrylamide gel electrophoresis (SDS-PAGE), followed by electroblotting onto polyvinylidene difluoride membranes (EMD Millipore, Billerica, MA, USA), and then blocked with $5 \%$ non-fat milk and incubated overnight at $4{ }^{\circ} \mathrm{C}$ with the following primary antibodies against Tisp 40 (1:100; sc-54800; Santa), $\alpha$-SMA (1:100; ab5694; Abcam), E-cadherin (1:100; 610181; BD Biosciences), collagen I (1:100; ab34710; Abcam), fibronectin (1:100; ab2413; Abcam), TGF- $\beta$ (1:100; 18978-1-AP, PTG), phosphor(p)Smad2/3 (D27F4; 1:100; Cell signaling technology), Smad2 (1:100; 12570-1-AP; PTG), Smad3 (1:100; 25494-1-AP; ATG) and Snail (1:100; ab180714; Abcam). Washed three times with Tris-buffered saline containing Tween-20 (TBST), the membranes were incubated with HRPconjugated goat anti-rabbit/mouse polyclonal secondary antibody (1:100; LK2001/ LK2003; Sungene Biotech.) for $1 \mathrm{~h}$ at room temperature. Target proteins were visualized and detected using Odyssey Infrared Imaging system Model 9120 (LI-COR Biotechnology, Lincoln, NE, USA) with Quantity-One software (Bio-Rad Laboratories, Inc.).

\section{Establishment of a stable cell line}

Fragments were retrieved by $1 \%$ agarose gel electrophoresis using an Agarose Gel Extraction Kit (Omega, D2500), after double-enzyme digestion of pUC57-Tisp40 and pLVX-mCMV-ZsGreen-IRESPuro (Wuhan Viraltherapy Technologies Co. Ltd) by EcoRI and SpeI (NEB), followed by connection by T4 DNA Ligase (BM121, Transgen BioTech, Beijing). The ligation product was transformed into JM109 (Wuhan Viraltherapy Technologies Co. Ltd). The plasmid was extracted using a Small Plasmid Extraction Kit (EM101, Transgen BioTech, Beijing) after the inoculation and amplification of single colonies, and the bacterial fluid was verified by sequencing. The sequencing primer was CMV-F, whose primer sequence is 5 '-CGCAAATGGGCGGTAGGCGTG-3'. Then, 293T cells were co-transfected with pLVX-Tisp40-ZsGreen-Puro (recombinant plasmid) or pLVX-ShRNA2-Puro (control plasmid) to obtain high-titer lentiviral (rLV-Tisp40 and rLV-ShRNA2) containing the target gene using a Lentiviral Packaging Kit (R003, Wuhan Viraltherapy Technologies Co. Ltd). When the TCMK-1 cells reached $80-$ $90 \%$ confluence, a total of $5 \times 105$ cells $/ \mathrm{ml}$ cells were transferred to cell plates, which were transfected with rLV-Tisp40 and rLV-ShRNA2 on the basis of MOI=20 the next day. Two days after transfection, lentivirus-infected TCMK-1 cells were selected using complete medium (DMEM supplemented with $10 \%$ fetal bovine serum and 1\% penicillin- streptomycin) containing $10 \mu \mathrm{g} / \mathrm{ml}$ puromycin. TCMK-1/ Tisp40 (Tisp40-overexpression group) and TCMK-1/vector cells (empty vector group) were obtained. 


\section{Cellular Physiology Cell Physiol Biochem 2017;42:697-712 \begin{tabular}{ll|l} 
and Biochemistry & $\begin{array}{l}\text { DOI: 10.1159/000477887 } \\
\text { Published online: June 13, } 2017\end{array}$ & $\begin{array}{l}\text { @ 2017 The Author(s). Published by S. Karger AG, Basel } \\
\text { www.karger.com/cpb }\end{array}$ \\
\cline { 2 - 3 }
\end{tabular} Xiao et al.: Tisp40 in Renal Tubulointerstitial Fibrosis}

Small-interfering RNA

RNA oligonucleotides for scramble (forward, 5'-CCUACGCCACCAAUUUCGUdTdT-3') (Bioneer); mouse siRNA1-Tisp40 (forward, 5'-CCCAAUAUGAUACACUGCUCAGAAA-3'), mouse siRNA2Tisp40 (forward, 5'-GGCCAACCUUCGGACUCAUCUCUAU-3'), mouse siRNA3-Tisp40 (forward, 5'-AGUAGAAGUUGGCCACUUCCAUGGG-3') [26] (Invitrogen) were synthesized. Each siRNA (100nM) was transfected into TCMK-1/wt cells using Lipofectamine RNA iMAX (Invitrogen) for at least 48h; cells were then harvested for RNA and protein preparation. The siRNA which had the strongest inhibitory effect was applied to this study.

\section{Immunofluorescence staining}

Cells were fixed in $4 \%$ paraformaldehyde for $30 \mathrm{~min}$ at room temperature and subsequently permeabilized with $0.1 \%$ Triton X-100 (BIOSHARP) for $10 \mathrm{~min}$ at room temperature. Following blocking in $10 \%$ donkey serum (ANT051; antGene), the cells were incubated with primary antibodies targeting fibronectin (1:200; ab2413; Abcam) overnight at $4^{\circ} \mathrm{C}$. The cells were then cultured with Alexa Fluor ${ }^{\circledR} 594$ donkey anti-rabbit IgG (1:400; A20207) and Alexa Fluor ${ }^{8} 594$ donkey anti-mouse IgG (1:400; A21203; both Invitrogen) for $30 \mathrm{~min}$ at $37^{\circ} \mathrm{C}$. The cell nuclei were stained with $4^{\prime} 6^{\prime}$-diamino-2phenylindole dihydrochloride (216276, Roche).

\section{Statistical analysis}

All data are presented as the mean \pm standard deviation (s.d). Analysis of variance was used to evaluate statistical significance. P-values $<0.05$ were regarded significant. All experiments were performed at least 3 times. Statistical analysis was conducted using SPSS 19.0.

\section{Results}

Expression of Tisp40 is elevated in the kidney of I/R-induced mice in vivo, and TGF- $\beta$ increased the expression of Tisp 40 in TCMK-1 cells dose-dependently and time-dependently First, we investigated whether the expression of Tisp40 in the kidney is changed by $\mathrm{I} / \mathrm{R}$. We found that the expression of Tisp40 was upregulated at both the mRNA level and the protein level in the kidneys of I/R-induced mice (Fig. 1A, 1B and 1C). Furthermore, IHC staining showed that Tisp40 expression was significantly higher in I/R-induced renal tubular epithelial cells (Fig. 1D and 1E). Consistently, TCMK-1/wt cells treated with TGF- $\beta$ also showed elevated expression of Tisp40, while unconditioned TCMK$1 /$ wt cells showed only limited expression of Tisp40 (Fig. 1F, 1G and 1H). Exogenous TGF- $\beta$ increased the expression of Tisp40 in TCMK- 1 cells. In addition, we confirmed that TGF- $\beta$ increased the expression of Tisp40 dose-dependently $(0.1,1$, or $10 \mathrm{ng} / \mathrm{ml})$ and time-dependently (from 0 to $48 \mathrm{~h}$ ) by Western blot (Fig. 1I, 1J and 1K). These results indicated that Tisp40 might be critical in renal fibrosis.

To determine the effects of Tisp40 on TGF- $\beta$-stimulated renal cellular fibrosis, we established a stable cell line, TCMK-1/Tisp40 (Fig. 1L), and knocked down endogenous Tisp40 by transfecting TCMK-1/wt cells with siRNA-Tisp40. We constructed three kinds of siRNA-Tisp40, and siRNA3-Tisp40 proved to have the strongest inhibitory effect based on Western blot (Fig. 1M and $1 \mathrm{~N}$ ).

Tisp40 enhanced ECM accumulation in cultured TGF- $\beta$-stimulated TCMK-1 cells

Next, we investigated the effects of Tisp40 on ECM accumulation in cultured TGF$\beta$-stimulated TCMK-1 cells. Fibronectin and collagen I were examined by Western blotting and qPCR, and fibronectin was also examined by immunofluorescence staining. Following treatment with TGF- $\beta$, the expression levels of fibronectin and collagen I increased significantly in cultured TCMK-1/Tisp40 cells compared to the control and the empty vector group (Fig. 2A, 2B, 2C, 2D, 2I and 2K) but decreased significantly in a cultured Tisp40-deficient TCMK-1 cell line (Fig. 2E, 2F, 2G, 2H, 2J and 2L). These results indicated that Tisp40 enhanced ECM accumulation in the cultured TGF- $\beta$-stimulated 


\section{Cellular Physiology Cell Physiol Biochem 2017;42:697-712 \begin{tabular}{l|l} 
DOI: 10.1159/000477887 & $\begin{array}{l}\text { @ 2017 The Author(s). Published by S. Karger AG, Basel } \\
\text { www.karger.com/cpb }\end{array}$ \\
\hline
\end{tabular}

A

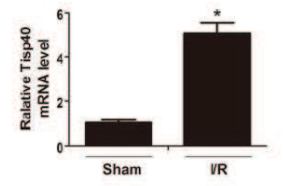

D

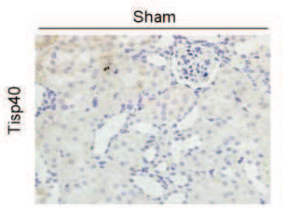

F

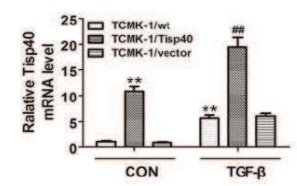

I

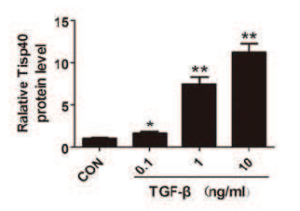

L

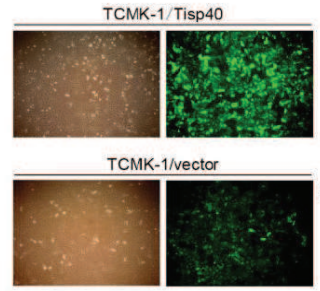

B

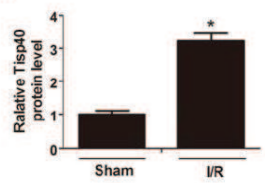

I/R

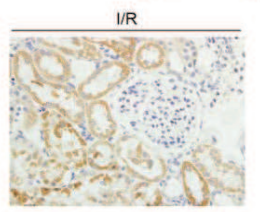

G

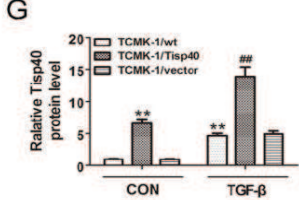

$\mathrm{J}$

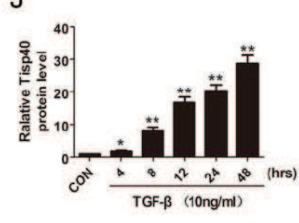

M

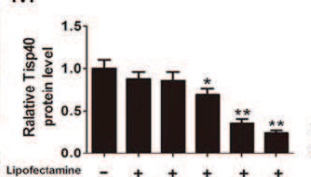

ipotectarine - +++++ RNA iMAX

SiRNA

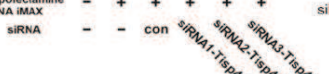

C

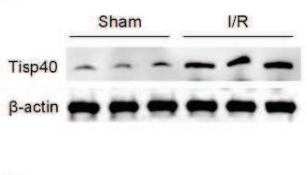

E

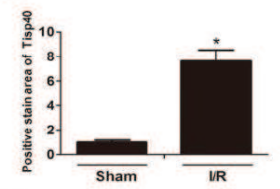

$\mathrm{H}$

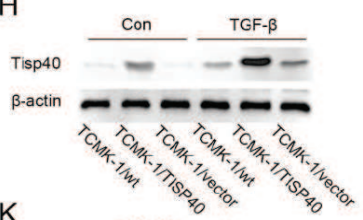

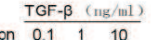

Tisp40

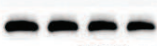

con $\frac{\text { TGF }-\beta(10 \mathrm{ng} / \mathrm{m} 1)}{4-8+12-24+48}$

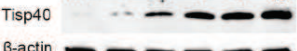

N

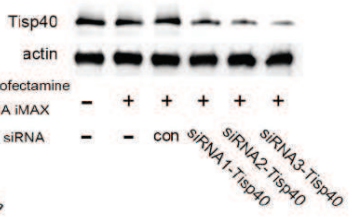

Fig. 1. Tisp40 is upregulated in I/R kidneys and TGF- $\beta$-induced TCMK- 1 cell line, and TGF- $\beta$ increased expression of Tisp40 in TCMK-1 cells dose-dependently and time-dependently. (A-C) Tisp40 measured by representative real-time reverse transcriptase polymerase chain reaction and Western blot analysis in the kidney of wild-type mice after ischemia-reperfusion (I/R); D, Tisp40 staining; Brown staining indicates immunopositivity ( $\times 400$ ); E, quantitative analysis of Tisp40 (brown area \%) from the sections; (F-H) Tisp40 measured by representative real-time reverse transcriptase polymerase chain reaction and Western blot analysis in TCMK-1/wt, TCMK-1/Tisp40, TCMK-1/vector cells after treatment of TGF- $\beta$; (I-K) Tisp40 measured by western blot analysis in TCMK- 1 /wt cells treated with different dose $(0.1,1$, or $10 \mathrm{ng} / \mathrm{ml})$ and period $(4,8,12,24,48 \mathrm{~h})$ of TGF- $\beta$; L, establishment of TCMK-1/ Tisp40 (Tisp40-overexpression group) and TCMK-1/vector cells (empty vector group); (M, N) Tisp40 measured by western blot analysis in TCMK-1/wt cells transfected by control siRNA, siRNA1-Tisp40, siRNA2-Tisp40 and siRNA3-Tisp40(all $100 \mathrm{nM}$ ), then treated with TGF- $\beta$. Protein level of $\beta$-actin was used as internal loading control. The data are shown as the mean \pm s.d. ${ }^{*} \mathrm{P}<0.05,{ }^{*} \mathrm{P}<0.01$ versus sham-operation (Sham) or control (Con) ( 0 ng/ml TGF- $\beta$ ); \#p $<0.05$, \#\#p $<0.01$ versus TGF- $\beta$-induced TCMK-1/wt cells.

TCMK-1 cell line, which supports the hypothesis that Tisp40 could be critical in renal fibrosis.

\section{Tisp40 aggravated EMT in TGF- $\beta$-stimulated TCMK-1 cells}

To confirm the effect of Tisp40 on EMT in TCMK-1 cells, the expression levels of $\alpha$-SMA (mesenchymal marker) and E-cadherin (epithelial marker) were examined by Western blotting and qPCR. Cellular exposure to TGF- $\beta$ resulted in a significant EMT, 


\section{Cellular Physiology Cell Physiol Biochem 2017;42:697-712 \begin{tabular}{l|l}
\cline { 2 - 2 } and Biochemistry $10.1159 / 000477887$ \\
Published online: June 13, 2017 & $\begin{array}{l}\text { @ 2017 The Author(s). Published by S. Karger AG, Basel } \\
\text { www.karger.com/cpb }\end{array}$ \\
\hline
\end{tabular} Xiao et al.: Tisp40 in Renal Tubulointerstitial Fibrosis}

Fig. 2. Tisp40 enhanced ECM accumulatiom in TGF$\beta$-induced TCMK-1 cell line. (A-D, I) fibronectin and collagen I measured by representative real-time reverse transcriptase polymerase chain reaction and Western blot analysis in TCMK-1/ wt, TCMK-1/Tisp40, TCMK$1 /$ vector cells treated with or without TGF- $\beta$; (E-G, J) fibronectin and collagen I measured by representative real-time reverse transcriptase polymerase chain reaction and Western blot analysis in TCMK-1/wt cells transfected by control siRNA or siRNA-Tisp40 (both $100 \mathrm{nM}$ ), then treated with or without TGF- $\beta$; $\mathrm{K}$, fibronectin detected by immunofluorescence in TCMK-1/wt and TCMK-1/ Tisp40 cells treated with or without TGF- $\beta(\times 400)$, fibronectin (red) and DAPI (blue); L; fibronectin detec-

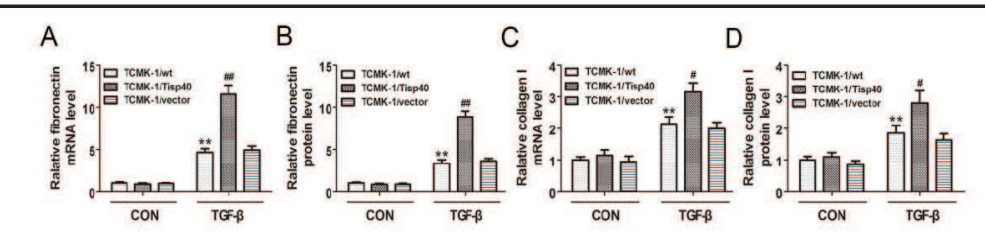

E $\quad F \quad$ G
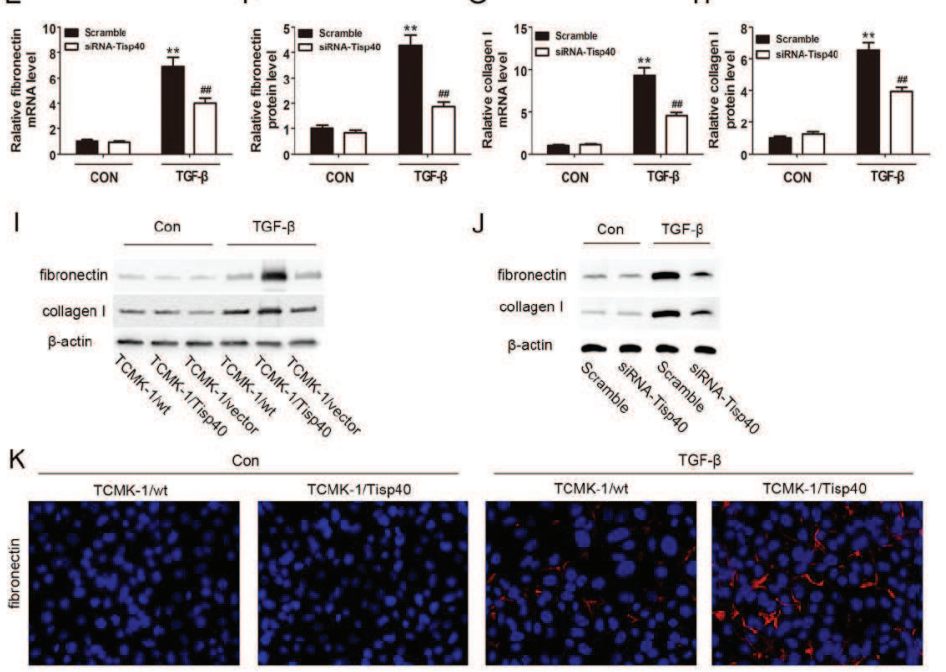

L
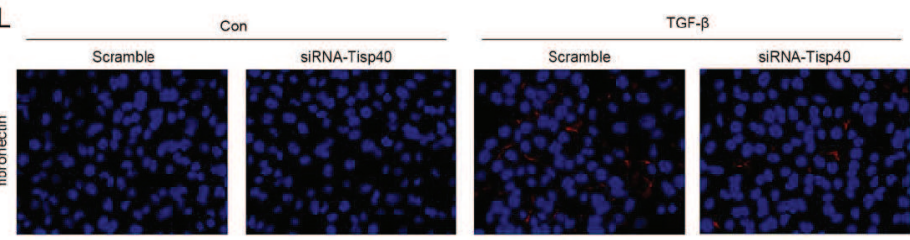

ted by immunofluorescence in TCMK-1/wt cells transfected by control siRNA or siRNA-Tisp40 (both $100 \mathrm{nM})$, then treated with or without TGF- $\beta(\times 400)$, fibronectin (red) and DAPI (blue). Protein level of $\beta$-actin was used as internal loading control. The data are shown as the mean \pm s.d. ${ }^{*} \mathrm{P}<0.05,{ }^{*} \mathrm{P}<0.01$ versus corresponding control (Con) ( $0 \mathrm{ng} / \mathrm{ml}$ TGF- $\beta$ ); \#p<0.05, \#\#p<0.01 versus TGF- $\beta$-induced TCMK$1 /$ wt cells or scramble.

characterized by a decrease in E-cadherin and an increase in $\alpha$-SMA, which aggravated by Tisp40 overexpression compared with the control and empty vector group (Fig. 3A, 3B, 3C, 3D and 3I) and relieved by Tisp40 silencing compared to the scramble group (Fig. 3E, 3F, 3G, 3H and 3J). These results suggest that Tisp40 aggravates the loss of the epithelial marker E-cadherin and increases the expression of the myofibroblast marker $\alpha$-SMA in TGF- $\beta$-stimulated renal epithelial cells, which reinforces the possibility Tisp40 could be critical in renal fibrosis.

Tisp40 knockout protects against I/R-induced renal fibrosis

After determining the effects of Tisp40 on TGF- $\beta$-stimulated renal cellular fibrosis in vitro, we investigated the protective effect of Tisp40 deficiency against renal fibrosis in vivo using Tisp40-knockout (Tisp40-/-) and wild-type (Tisp40+/+). We compared renal pathologic changes in renal fibrosis mice of both genotypes induced by I/R. We confirmed that Tisp40 was not expressed in the kidneys of Tisp40-/- mice by Western blot and qPCR (Fig. 4A, 4B and 4C). Masson trichrome staining and hydroxyproline analysis suggested that the kidneys of wild-type mice exhibited significantly elevated atrophy and necrosis of tubular and interstitial fibrosis after induction by I/R. By contrast, the renal fibrosis in Tisp40-/- mice induced by I/R was markedly attenuated (Fig. 4D, 4E and 4F). Furthermore, IHC staining revealed that, relative to Tisp40+/+ 


\section{Cellular Physiology Cell Physiol Biochem 2017;42:697-712 \begin{tabular}{l|l} 
DOI: 10.1159/000477887 2017 & O 2017 The Author(s). Published by S. Karger AG, Basel \\
and Bumbarge
\end{tabular}
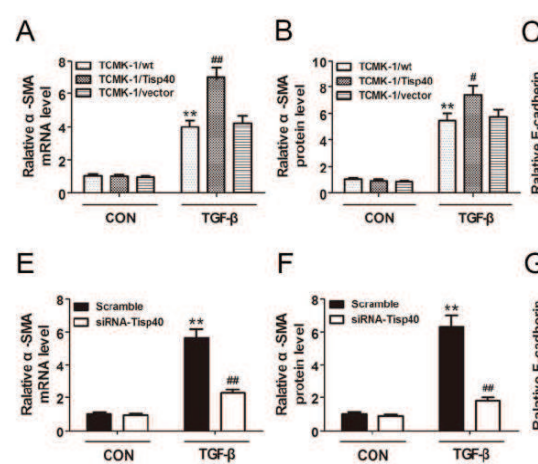

$\mathrm{F} \quad \mathrm{G}$

C D

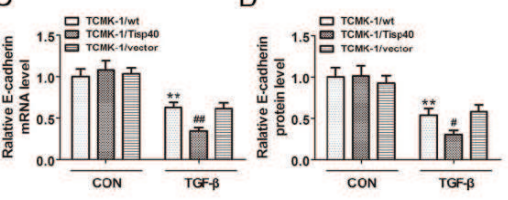

$\mathrm{H}$

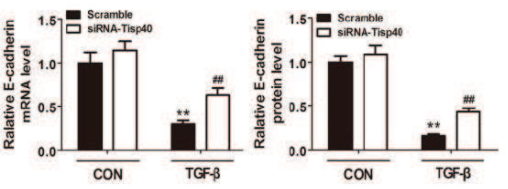

I

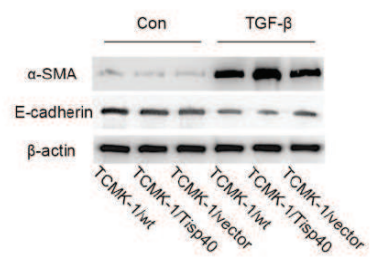

$J$

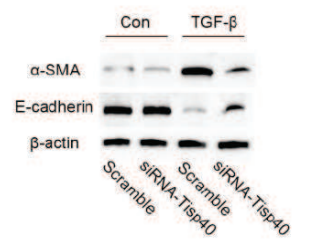

Fig. 3. Tisp40 aggravated EMT in TGF- $\beta$-induced TCMK- 1 cell line. (A-D, I) $\alpha$-SMA and E-cadherin measured by representative real-time reverse transcriptase polymerase chain reaction and Western blot analysis in TCMK-1/wt, TCMK-1/Tisp40, TCMK-1/vector cells treated with or without TGF- $\beta$; (E-G, J) $\alpha$-SMA and E-cadherin measured by representative real-time reverse transcriptase polymerase chain reaction and Western blot analysis in TCMK-1/wt cells transfected by control siRNA or siRNA-Tisp40 (both $100 \mathrm{nM}$ ), then treated with or without TGF- $\beta$. Protein level of $\beta$-actin was used as internal loading control. The data are shown as the mean \pm s.d. ${ }^{*} \mathrm{P}<0.05,{ }^{*} \mathrm{P}<0.01$ versus corresponding control (Con) (0 ng/ml TGF- $\beta$ ); \#p<0.05, \#\#p<0.01 versus TGF- $\beta$-induced TCMK-1/wt cells or scramble.

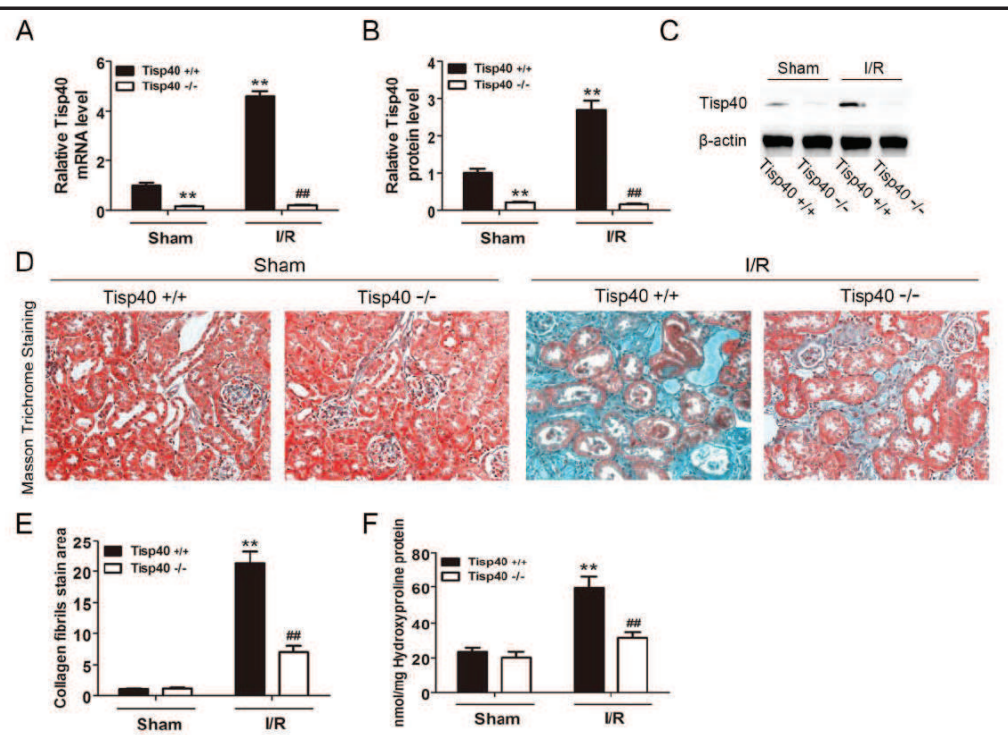

Fig. 4. Tisp40-knockout mice are protected against I/R-induced renal fibrosis. (A-C) Tisp40 measured by representative real-time reverse transcriptase polymerase chain reaction and Western blot analysis in kidneys of wild-type mice and Tisp40-knockout mice induced by ischemia-reperfusion (I/R) or not; D, Masson staining $(\times 400)$; E, quantitative analysis of the extent of collagen fibrils (blue area $\%$ ) from the sections; F, hydroxyproline analysis. Protein level of $\beta$-actin was used as internal loading control. The data are shown as the mean \pm s.d. ${ }^{*} \mathrm{P}<0.05,{ }^{*} \mathrm{P}<0.01$ versus corresponding sham-operation (Sham); $\# \mathrm{p}<0.05, \# \# \mathrm{p}<0.01$ versus I/R-induced wild-type.

\section{KARGER}




\section{Cellular Physiology \\ Cell Physiol Biochem 2017;42:697-712 and Biochemistry
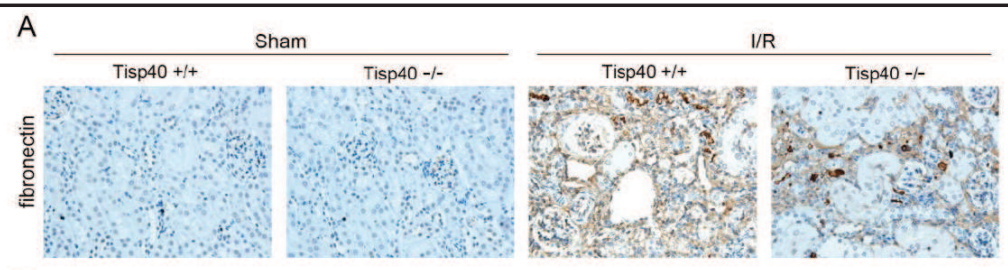

B

Sham
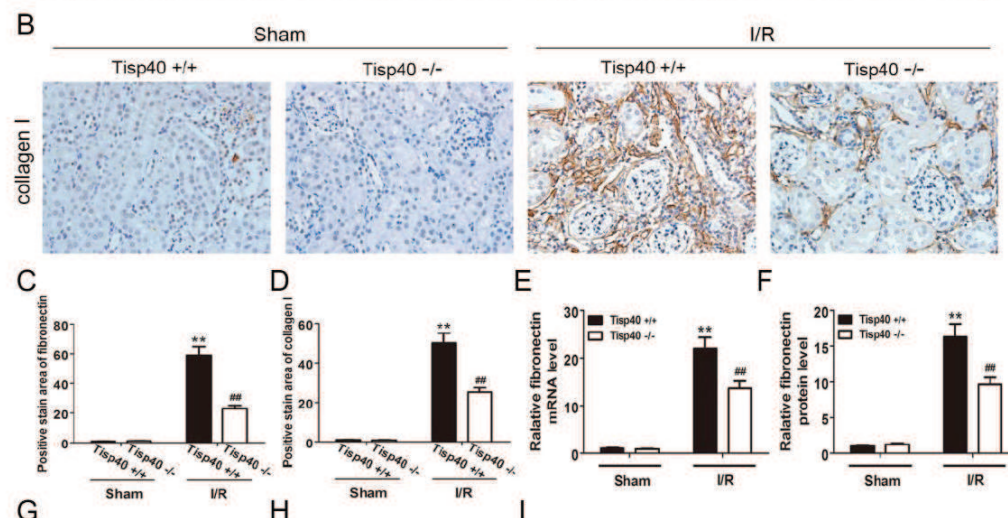

E

F

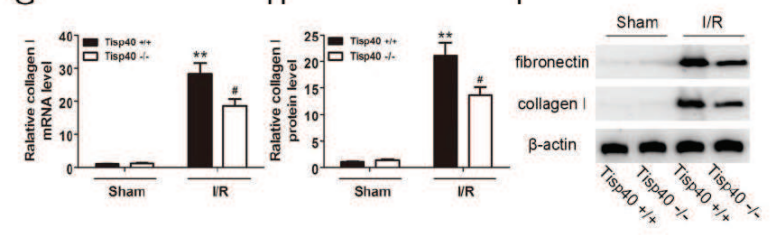

Fig. 5. Tisp40-knockout mice are protected against I/R-induced ECM accumulation. A, fibronectin staining; B, collagen I staining; Brown staining indicates immunopositivity $(\times 400)$. C, quantitative analysis of fibronectin (brown area \%) from the sections; D, quantitative analysis of collagen I (brown area \%) from the sections; (E-H) fibronectin and collagen I measured by representative real-time reverse transcriptase polymerase chain reaction and Western blot analysis in kidneys of wild-type mice and Tisp40-knockout mice induced by ischemia-reperfusion (I/R) or not. Protein level of $\beta$-actin was used as internal loading control. The data are shown as the mean \pm s.d. ${ }^{*} \mathrm{P}<0.05,{ }^{*} \mathrm{P}<0.01$ versus corresponding sham-operation (Sham); \#p<0.05, \#\#p<0.01 versus I/R-induced wild-type.

mice, Tisp40-/- mice exhibited significantly lower levels of ECM accumulation, collagen I and fibronectin (Fig. 5A, 5B, 5C and 5D). The mRNA and protein expression was further examined by qPCR and Western blot (Fig. 5E, 5F, 5G, 5H and 5I). In addition, we explored the difference of EMT in mice of both genotypes induced by I/R, and compared with Tisp40-/- mice, Tisp40+/+ mice showed a more serious EMT, characterized by a decrease in E-cadherin and an increase in $\alpha$-SMA (Fig. 6).

The inhibitory effect of Tisp40 deficiency on renal fibrosis requires modulation of Smad2 and Smad3 phosphorylation

Considering the well-characterized role of Smad 2 and Smad3 as key downstream mediators in the TGF- $\beta$ signaling pathway of renal fibrosis [27], we investigated whether the inhibitory signal-mediated process of Tisp 40 deficiency in renal fibrosis requires Smad2/3. To study signal transduction pathways, we first confirmed that the levels of both total and phosphor-Smad2/3 in kidneys are higher in I/R-induced mice than in control mice (Fig. 7A, 7B, 7C and 7D). We next found that there was no difference in TGF- $\beta$, Smad2 and Smad3 in I/R-induced kidneys between Tisp40-/- mice and wildtype mice (Fig. 7G, 7H, 7I, 7J and 7L), but both pSmad2 and pSmad3 were significantly inhibited in the kidneys of Tisp40-/- mice induced by I/R (Fig. 7E, 7F, 7K and 7L). These results suggested that Tisp40 deficiency provides a protective effect against renal 


\section{Cellular Physiology Cell Physiol Biochem 2017;42:697-712 \begin{tabular}{l|l|l} 
and Bioch 10.1159/000477887 & $\begin{array}{l}\text { () } 2017 \text { The Author(s). Published by S. Karger AG, Basel } \\
\text { www.karger.com/cpb }\end{array}$ \\
\hline
\end{tabular}}

Fig. 6. Tisp40-knockout mice are protected against I/R-induced ECM accumulation. A, $\alpha$-SMA staining; B, E-cadherin staining; Brown staining indicates immunopositivity $(\times 400) ; C$, quantitative analysis of $\alpha$-SMA (brown area \%) from the sections; $D$, quantitative analysis of E-cadherin (brown area \%) from the sections; (E-H) $\alpha$-SMA and E-cadherin measured by representative real-time reverse transcriptase polymerase chain reaction and Western blot analysis in kidneys of wild-type mice and Tisp40-knockout mice induced by ischemia-reperfusion (I/R) or not. Protein level of $\beta$-actin was used as internal loading control. The data are shown as the mean \pm s.d. ${ }^{*} \mathrm{P}<0.05$, $* \mathrm{P}<0.01$ versus correspon-

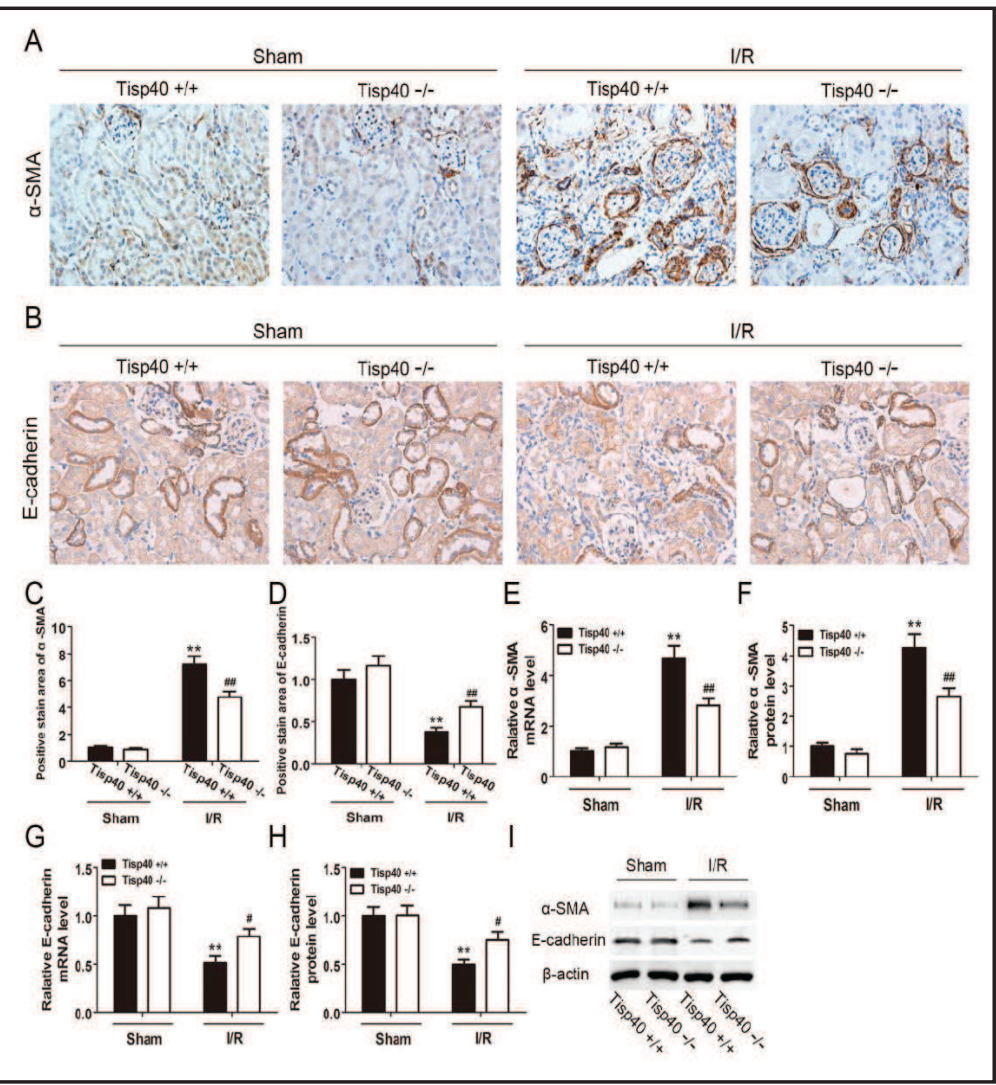

ding sham-operation (Sham); \#p<0.05, \#\#p<0.01 versus I/R-induced wild-type.

fibrosis induced by IRI without modulating the renal expression of TGF- $\beta$, Smad 2 and Smad3 rather than inhibiting the phosphorylation of Smad2 and Smad3 in I/R-induced kidneys. In our in vitro study, Tisp40 overexpression upregulated the expression of pSmad2/3 without modulation of Smad2 and Smad3 (Fig. 8A, 8B, 8C and 8G). In contrast, when Tisp40 was knocked down by transfection with siRNA-Tisp40, the TGF$\beta$-induced pSmad $2 / 3$ level was reduced (Fig. $8 \mathrm{D}, 8 \mathrm{E}, 8 \mathrm{~F}$ and $8 \mathrm{H}$ ). These results provided further evidence that renal fibrosis suppressed by Tisp40 deficiency is mediated by the downregulation of Smad2/3 phosphorylation.

\section{Inhibition of Tisp40 decreases Snail signaling}

Snail has been shown to be a key EMT-regulatory gene in tubular epithelial cells [28]. In the process of EMT, the expression of E-cadherin and $\alpha$-SMA was proven years ago to be concomitant with Snail protein $[29,30]$. Considering the relationship between Snail and EMT, we then investigated the expression of Snail in vitro and in vivo to examine the underlying mechanism of Tisp40 deficiency-inhibited EMT. To investigate whether Tisp40 affects Snail signaling, we first determined that TGF- $\beta$ promoted the expression of Snail. The expression of TGF- $\beta$-stimulated Snail in TCMK- 1 /Tisp 40 cells was markedly higher than that in the control and empty vector group (Fig. 9F, 9G and 9J). In contrast, when Tisp40 was knocked down by transfection with siRNA-Tisp40, the TGF- $\beta$-induced Snail level was reduced (Fig. 9H, 9I and 9K). These results in vitro tentatively confirmed our assumption that the inhibition of Tisp40 decreases Snail signaling. Snail was significantly inhibited in the I/R-induced kidneys of Tisp40-knockout mice compared with wild-type mice (Fig. 9A, 9B, 9C, 9D and 9E), which confirms that Tisp40 deficiency is mediated by Snail downregulation to inhibit EMT.

\section{KARGER}




\section{Cellular Physiology Cell Physiol Biochem 2017;42:697-712

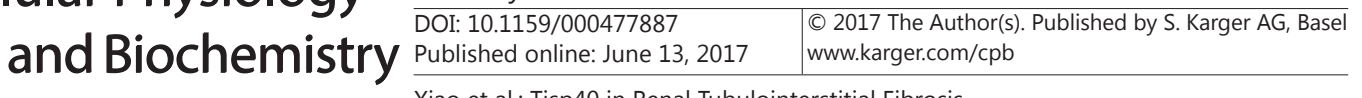

Fig. 7. IRI activates TGF- $\beta /$ Smad signaling, and Tisp40-deficiency inhibits I/R-induced renal fibrosis by modulating Smad2 and Smad3 phosphorylation without modulating renal expression of TGF- $\beta$ directly. (A-D) Smad2, Smad3 and pSmad2/3 measured by western blot analysis in the kidney of wild-type mice after is chemia-reperfusion (I/R); E, pS$\operatorname{mad} 2 / 3$ staining; Brown staining indicates immunopositivity $(\times 400) ; \quad F$, quantitative analysis of pSmad2/3 (brown area \%) from the sections; ( $G, H, L$ ) TGF- $\beta$ measured by

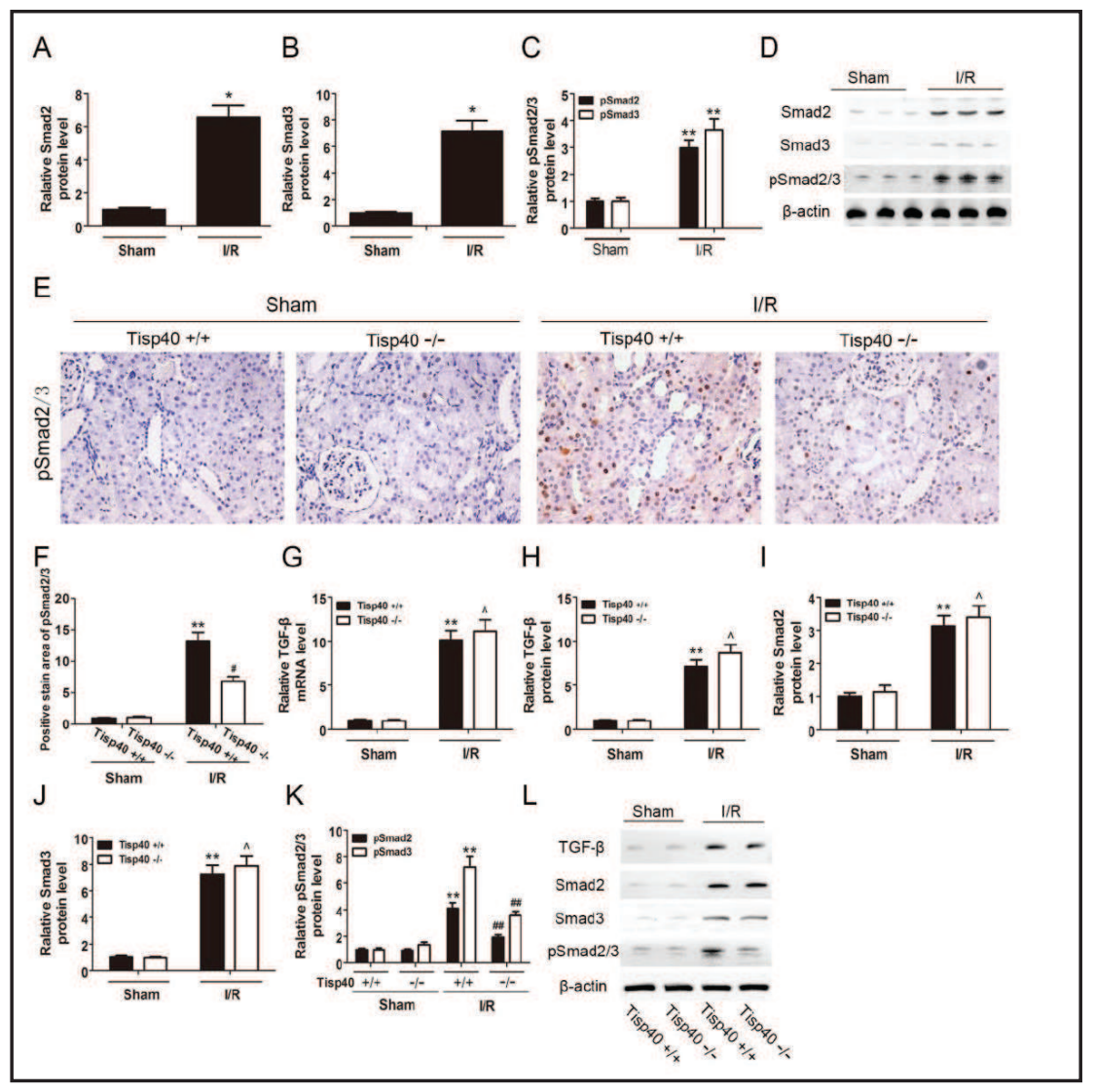
representative real-time reverse transcriptase polymerase chain reaction and Western blot analysis in kidneys of wild-type mice and Tisp40-knockout mice induced by ischemia-reperfusion (I/R) or not; (I-L) Smad2, Smad3 and pSmad2/3 measured by western blot analysis in in kidneys of wild-type mice and Tisp40-knockout mice induced by ischemia-reperfusion (I/R) or not. Protein level of $\beta$-actin was used as internal loading control. The data are shown as the mean \pm s.d. ${ }^{*} \mathrm{P}<0.05,{ }^{*} \mathrm{P}<0.01$ versus corresponding sham-operation (Sham); $\# p<0.05, \# \# p<0.01$ and ${ }^{\wedge} p>0.05$ versus I/R-induced wild-type.

\section{Discussion}

Renal IRI develops easily into chronic renal failure through inflammatory interstitial fibrosis, whose mechanism has not been fully clarified [2-4]. Thus, studying the biological networks, especially transcription factors, is an indispensable process in research on developing therapies to inhibit and delay kidney fibrosis against kidney disease. Our study showed for the first time that Tisp40 (41 kDa) is involved in renal tubulointerstitial fibrosis. Tisp40 deficiency inhibited TGF- $\beta$-stimulated EMT and ECM accumulation in renal tubular epithelial cells and prevented pathological changes of renal fibrosis by I/R. Furthermore, the inhibitory effect of Tisp40 deficiency on renal fibrosis was related to the downregulation of Smad2/3 phosphorylation.

ER-resident transcription factors are involved in the regulation of various biological processes, including cell maturation, differentiation and maintenance of cellular homeostasis [31]. Tisp40, as a member, has been proven to play an important role in the differentiation of intestinal goblet and Paneth cells [32] and in spermatogenesis $[22,33]$. In this study, we explored the mechanism of Tisp40's involvement in renal fibrosis. We showed that Tisp40 expression was elevated following I/R; in other words, the expression of Tisp40 was increased by ischemic injury. The tubular epithelial 


\section{Cellular Physiology Cell Physiol Biochem 2017;42:697-712 \begin{tabular}{ll|l} 
and Biochemistry & $\begin{array}{l}\text { DOI: } 10.1159 / 000477887 \\
\text { Published online: June 13, } 2017\end{array}$ & $\begin{array}{l}\text { O 2017 The Author(s). Published by S. Karger AG, Basel } \\
\text { www.karger.com/cpb }\end{array}$ \\
\cline { 2 - 3 }
\end{tabular}

Fig. 8. Tisp40-deficiency inhibits TGF- $\beta$-induced cellular fibrosis by modulating Smad2 and Smad3 phosphorylation. (A-C, G) Smad2, Smad3 and pSmad2/3 measured by western blot analysis in TCMK-1/wt, TCMK-1/ Tisp40, TCMK-1/vector cells treated with or without TGF- $\beta$; (D-F, H) Smad2, Smad3 and pSmad2/3 measured by western blot analysis in TCMK-1 cells transfected by control siRNA or siRNA-Tisp40 (both $100 \mathrm{nM}$ ), then treated with or without TGF- $\beta$. Protein level of $\beta$-actin was used as internal loading control. The data are shown as the mean \pm s.d. ${ }^{*} \mathrm{P}<0.05,{ }^{*} \mathrm{P}<0.01$

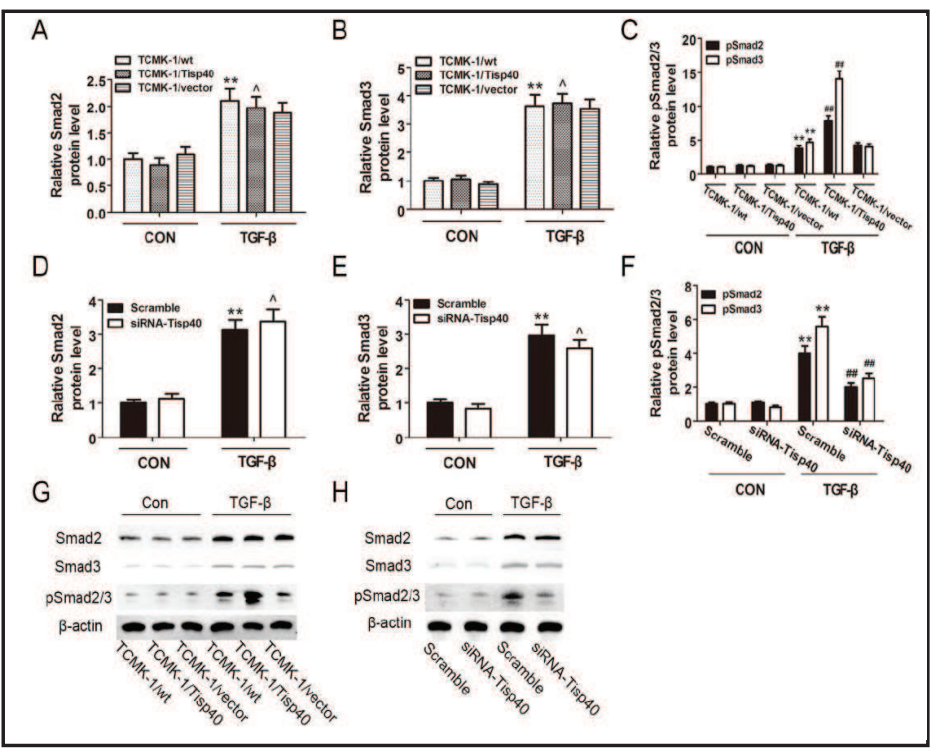
versus corresponding control (Con) $\left(0 \mathrm{ng} / \mathrm{ml} \mathrm{TGF-} \beta\right.$ ); $\# \mathrm{p}<0.05$, \#\#p<0.01 and ${ }^{\wedge} \mathrm{p}>0.05$ versus TGF- $\beta$ induced TCMK-1/wt cells or scramble.

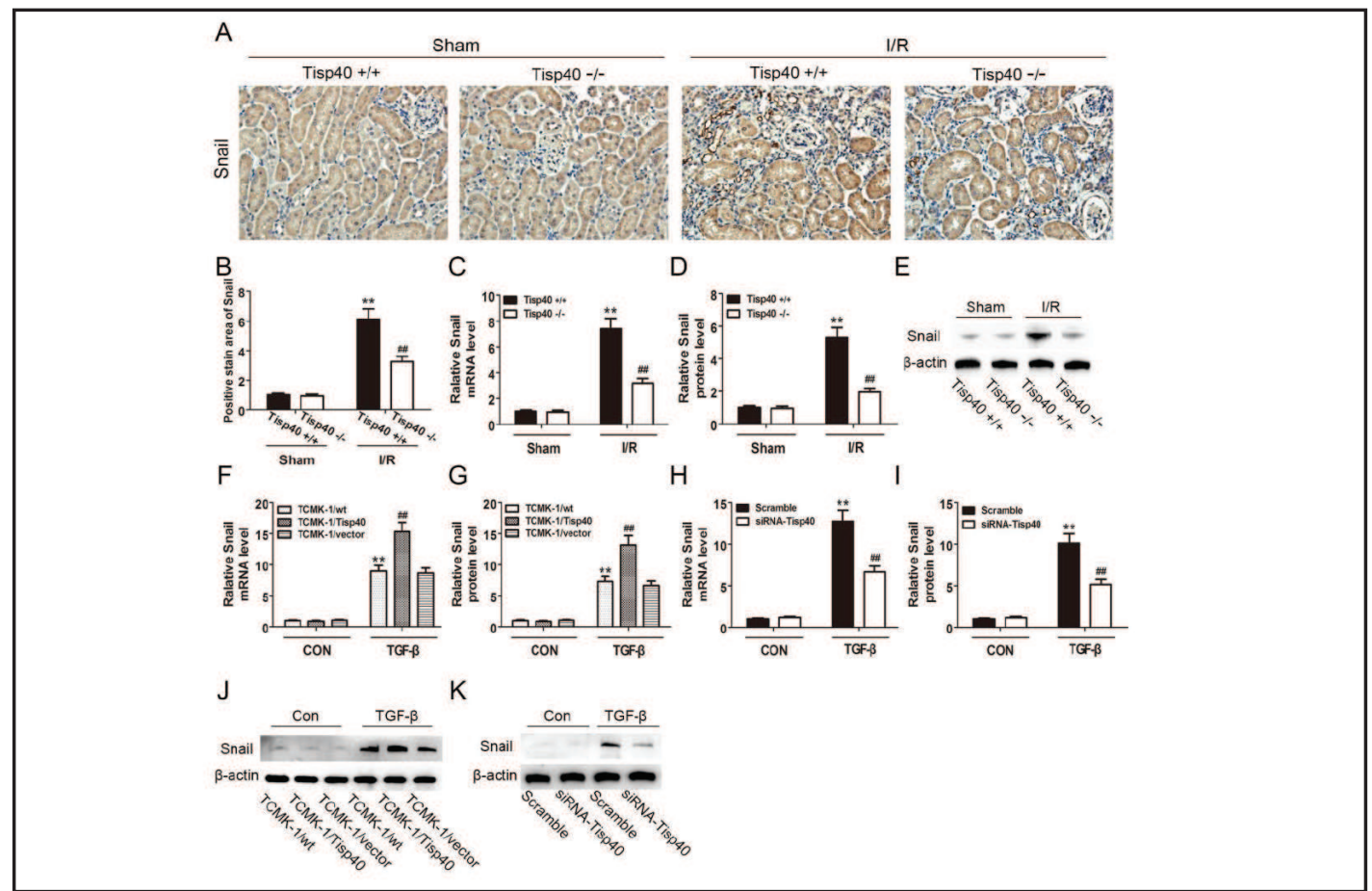

Fig. 9. Tisp40-deficiency decreases Snail signaling. A, Snail staining; Brown staining indicates immunopositivity ( $\times 400$ ); B, quantitative analysis of Snail (brown area \%) from the sections; (C-E) Snail measured by representative real-time reverse transcriptase polymerase chain reaction and Western blot analysis in kidneys of wild-type mice and Tisp40-knockout mice induced by ischemia-reperfusion (I/R) or not; (F, G, J) Snail measured by representative real-time reverse transcriptase polymerase chain reaction and Western blot analysis in TCMK-1/wt, TCMK-1/Tisp40, TCMK-1/vector cells treated with or without TGF- $\beta$; (H, I, K) Snail measured by representative real-time reverse transcriptase polymerase chain reaction and Western blot analysis in TCMK-1 cells transfected by control siRNA or siRNA-Tisp40 (both $100 \mathrm{nM}$ ), then treated with or without TGF- $\beta$. Protein level of $\beta$-actin was used as internal loading control. The data are shown as the mean \pm s.d. ${ }^{*} \mathrm{P}<0.05,{ }^{*} \mathrm{P}<0.01$ versus sham-operation (Sham) or control (Con) (0 ng/ml TGF- $\beta$ ); \#p<0.05, \#\#p<0.01 versus I/R-induced wild-type, TGF$\beta$-induced TCMK-1/wt cells or scramble.

\section{KARGER}




\section{Cellular Physiology Cell Physiol Biochem 2017;42:697-712

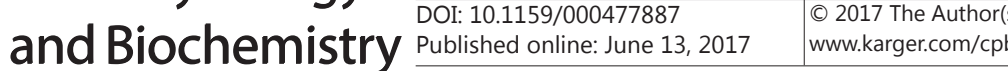

cells exposed to injury stimulation undergo de-differentiation and release profibrotic mediators [10-13, 15]. Excessive exposure to profibrotic cytokines leads to the acquisition of mesenchymal markers and the loss of epithelial cells [34]. As a central component of the cell adhesion junction, E-cadherin is required for epithelial formation to maintain epithelial homeostasis. The loss of E-cadherin and excessive $\alpha$-SMA are the most important aspects of EMT $[35,36]$.

To explore whether Tisp40 plays a beneficial role in renal fibrosis, we conducted an experiment in vitro. We found that the expression levels of $\alpha$-SMA, fibronectin, and collagen I was increased and the expression of E-cadherin attenuated in cultured TCMK-1/Tisp40 cells, which demonstrates aggravated EMT and ECM accumulation. To further confirm that Tisp40 is critical in renal fibrosis, we measured the TGF- $\beta$ stimulated expression of genes related to fibrosis in cultured renal tubular epithelial cells transfected with siRNA-Tisp40. As expected, the knockdown of Tisp40 blocked the expression of fibrosis-related genes, suggesting a strong possibility that Tisp40 is involved in I/R-induced renal fibrosis and that Tisp40 deficiency has a protective effect against I/R-induced tubulointerstitial fibrosis. This conclusion was further confirmed in vivo. The IR-induced atrophy and necrosis of tubular and tubulointerstitial fibrosis was markedly attenuated in Tisp40 knockout mice compared with wild-type mice.

TGF- $\beta$, a typical fibrogenic cytokine associated with EMT and ECM protein accumulation in renal diseases, is elevated not only in human patients but also in animal models of renal fibrosis $[17,18]$. Given the crucial role of TGF- $\beta$ in renal fibrosis, we asked how TGF- $\beta$ correlated with Tisp40. We found that TGF- $\beta$ time- and dose-dependently increased the expression levels of Tisp40 in cultured renal cells. In a variety of renal diseases, highly expressed TGF- $\beta$ can phosphorylate downstream factors Smad2/3 to induce the development of tubulointerstitial fibrosis, causing EMT and increasing ECM accumulation [37-39]. TGF- $\beta$ exerts multiple biological effects by initiating canonical and non-canonical pathways, among which Smads signaling is recognized as crucial in renal tubulointerstitial fibrosis. During fibrogenesis, Smad2/3 are highly activated and are associated with Smad7 inhibition via an ubiquitin E3-ligase-dependent degradation mechanism [40]. Multiple previous studies have demonstrated renal fibrosis can be effectively attenuated both in vivo and in vitro by blocking TGF- $\beta /$ Smad signaling in a variety of ways (neutralizing antibodies, antisense oligonucleotides and inhibitors) [41-43]. In this study, we confirmed that Smad2/3 were activated in I/R-induced kidneys and cultured TGF- $\beta$-stimulated renal tubular epithelial cells. In addition, we asked whether the protective effect of Tisp 40 deficiency is mediated by modulating the renal expression of TGF- $\beta$ directly. However, no change in the expression of TGF- $\beta$ was detected between Tisp40-deficient mice and wild-type mice. This result suggests that the antifibrotic effect of Tisp40 deficiency does not suppress the renal expression of TGF- $\beta$ directly. Subsequently, our research results confirmed that Smad2 and Smad3 expression showed no difference between Tisp40-deficient mice and wild-type mice as well as different groups in vitro. In other words, in both in vivo and in vitro experiments, Smad2/3 show no relationship to Tisp40. Interestingly, in Tisp40-deficient I/R mice, pSmad2/3 were expressed at lower levels. Consistently, Smad2/3 phosphorylation was reduced in TGF- $\beta$-stimulated TCMK- $1 /$ wt cells treated with siRNA-Tisp40 but increased in TCMK-1/Tisp40 cells. These results showed that the downregulation of Tisp40 facilitated the phosphorylation of Smad2/3 but had no direct effect on Smad2 and Smad3.

The zinc finger transcription factor Snail is a key molecule that triggers the process of tubular EMT. Snail can bind to a specific DNA sequence (CANNTG, where $\mathrm{N}$ is any nucleotide), called E-boxes, in the promoter of the E-cadherin gene to repress E-cadherin transcription $[44,45]$. Given the role of Snail in EMT, we investigated the correlation between Snail and Tisp40. We confirmed that Snail was activated in I/R-induced kidneys and cultured TGF- $\beta$-stimulated renal tubular epithelial cells. Moreover, we found that Tisp40 was closely related to Snail, and Tisp40 downregulation decreased the 


\section{Cellular Physiology Cell Physiol Biochem 2017;42:697-712 \begin{tabular}{ll|l} 
and Biochemistry & $\begin{array}{l}\text { DOI: 10.1159/000477887 } \\
\text { Published online: June 13, } 2017\end{array}$ & $\begin{array}{l}\text { (c) } 2017 \text { The Author(s). Published by S. Karger AG, Basel } \\
\text { www.karger.com/cpb }\end{array}$ \\
\hline
\end{tabular} Xiao et al.: Tisp40 in Renal Tubulointerstitial Fibrosis}

expression of Snail. These results suggest that Tisp 40 deficiency decreases Snail protein expression in vitro and in vivo. The mechanism by which Tisp40 deficiency inhibits renal EMT and ECM accumulation remains unknown. Most likely, multiple pathways are involved in the inhibitory effect of Tisp40 deficiency, and Smad2/3 activation and Snail expression may be the major events during the process. Tisp40 downregulation relieves renal tubulointerstitial fibrosis by suppressing the TGF- $\beta / \operatorname{Smad} 2 / 3$ pathway and subsequently inhibiting Snail expression. It is also possible that Snail might also be a potential target of Tisp40. The exact target of Tisp40 and the mechanism by which Tisp40 affects renal tubulointerstitial fibrosis need to be further elucidated.

Previous studies have shown that MAPKs (p38, ERK, JNK) can regulate the phosphorylation of Smad2/3 driven by TGF- $\beta$ [46-48]. In considering the role of MAPKs in phosphorylating Smad2/3, we cannot exclude the possibility that Tisp40 deficiency inhibits renal fibrosis via MAPKs or that one or several MAPK signaling processes are involved in the antifibrotic effect of Tisp40-deficiency. These possibilities should be investigated in our future studies.

In conclusion, our results show that Tisp40 is involved in the process of renal fibrosis. The knockdown of Tisp40 inhibits EMT and ECM accumulation. This reduction is associated with the downregulation of Smad2/3 phosphorylation. In addition, Snail, an important downstream mediator of the TGF- $\beta /$ Smads signaling pathway, is important in the process. Given the above, Tisp40 could be a useful therapeutic target in the fight against renal interstitial fibrosis.

\section{Acknowledgements}

This study was supported by the National Natural Science Foundation of China (grant no. 81470923 and no. 81470374).

\section{Disclosure Statement}

All author declare no conflicts of interest.

\section{References}

1 Jha V, Garcia-Garcia G, Iseki K, Li Z, Naicker S, Plattner B, Saran R, Wang AY, Yang CW: Chronic kidney disease: Global dimension and perspectives. Lancet 2013;382:260-272.

-2 Zeisberg M, Neilson EG: Mechanisms of tubulointerstitial fibrosis. J Am Soc Nephrol 2010;21:18191834.

- 3 Coca SG, Yusuf B, Shlipak MG, Garg AX, Parikh CR: Long-term risk of mortality and other adverse outcomes after acute kidney injury: A systematic review and meta-analysis. Am J Kidney Dis 2009;53:961-973.

-4 Venkatachalam MA, Griffin KA, Lan R, Geng H, Saikumar P, Bidani AK: Acute kidney injury: A springboard for progression in chronic kidney disease. Am J Physiol Renal Physiol 2010;298:F1078-F1094.

5 Ishani A, Xue JL, Himmelfarb J, Eggers PW, Kimmel PL, Molitoris BA, Collins AJ: Acute kidney injury increases risk of ESRD among elderly. J Am Soc Nephrol 2009;20:223-228.

-6 Iwano M, Plieth D, Danoff TM, Xue C, Okada H, Neilson EG: Evidence that fibroblasts derive from epithelium during tissue fibrosis. J Clin Invest 2002;110:341-350.

-7 Hung TW, Tsai JP, Lin SH, Lee CH, Hsieh YH, Chang HR: Pentraxin 3 activates JNK signaling and regulates the Epithelial-To-Mesenchymal transition in renal fibrosis. Cell Physiol Biochem 2016;40:1029-1038. 


\section{Cellular Physiology Cell Physiol Biochem 2017;42:697-712

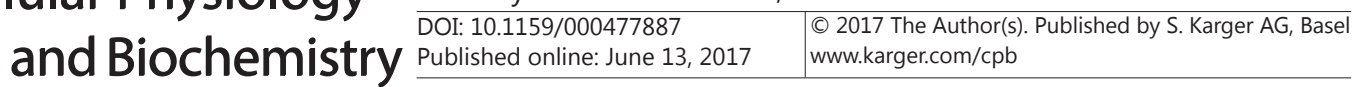 \\ Xiao et al.: Tisp40 in Renal Tubulointerstitial Fibrosis}

8 Zeisberg M, Duffield JS: Resolved: EMT produces fibroblasts in the kidney. J Am Soc Nephrol 2010;21:1247-1253.

-9 Strutz F, Okada H, Lo CW, Danoff T, Carone RL, Tomaszewski JE, Neilson EG: Identification and characterization of a fibroblast marker: FSP1. J Cell Biol 1995;130:393-405.

10 Hu J, Zhu Q, Li PL, Wang W, Yi F, Li N: Stem cell conditioned culture media attenuated albumininduced epithelial-mesenchymal transition in renal tubular cells. Cell Physiol Biochem 2015;35:17191728.

-11 Grgic I, Campanholle G, Bijol V, Wang C, Sabbisetti VS, Ichimura T, Humphreys BD, Bonventre JV: Targeted proximal tubule injury triggers interstitial fibrosis and glomerulosclerosis. Kidney Int 2012;82:172-183.

-12 Grande MT, Sanchez-Laorden B, Lopez-Blau C, De Frutos CA, Boutet A, Arevalo M, Rowe RG, Weiss SJ, Lopez-Novoa JM, Nieto MA: Snail1-induced partial epithelial-to-mesenchymal transition drives renal fibrosis in mice and can be targeted to reverse established disease. Nat Med 2015;21:989-997.

-13 Lovisa S, LeBleu VS, Tampe B, Sugimoto H, Vadnagara K, Carstens JL, Wu CC, Hagos Y, Burckhardt BC, Pentcheva-Hoang T, Nischal H, Allison JP, Zeisberg M, Kalluri R: Epithelial-to-mesenchymal transition induces cell cycle arrest and parenchymal damage in renal fibrosis. Nat Med 2015;21:998-1009.

14 Bonventre JV, Yang L: Cellular pathophysiology of ischemic acute kidney injury. J Clin Invest 2011;121:4210-4221.

- 15 Wu CF, Chiang WC, Lai CF, Chang FC, Chen YT, Chou YH, Wu TH, Linn GR, Ling H, Wu KD, Tsai TJ, Chen YM, Duffield JS, Lin SL: Transforming growth factor beta-1 stimulates profibrotic epithelial signaling to activate pericyte-myofibroblast transition in obstructive kidney fibrosis. Am J Pathol 2013;182:118-131.

16 Thadhani R, Pascual M, Bonventre JV: Acute renal failure. N Engl J Med 1996;334:1448-1460.

17 Bottinger EP: TGF-beta in renal injury and disease. Semin Nephrol 2007;27:309-320.

18 Meng XM, Tang PM, Li J, Lan HY: TGF-beta/Smad signaling in renal fibrosis. Front Physiol 2015;6:82.

19 Lan HY, Chung AC: TGF-beta/Smad signaling in kidney disease. Semin Nephrol 2012;32:236-243.

20 Asada R, Kanemoto S, Kondo S, Saito A, Imaizumi K: The signalling from endoplasmic reticulumresident bZIP transcription factors involved in diverse cellular physiology. J Biochem 2011;149:507518.

21 Qi H, Fillion C, Labrie Y, Grenier J, Fournier A, Berger L, El-Alfy M, Labrie C: AIbZIP, a novel bZIP gene located on chromosome 1q21.3 that is highly expressed in prostate tumors and of which the expression is up-regulated by androgens in LNCaP human prostate cancer cells. Cancer Res 2002;62:721-733.

22 Adham IM, Eck TJ, Mierau K, Muller N, Sallam MA, Paprotta I, Schubert S, Hoyer-Fender S, Engel W: Reduction of spermatogenesis but not fertility in Creb3l4-deficient mice. Mol Cell Biol 2005;25:76577664 .

23 Labrie C, Lessard J, Ben AS, Savard MP, Pelletier M, Fournier A, Lavergne E, Calvo E: Androgenregulated transcription factor AIbZIP in prostate cancer. J Steroid Biochem Mol Biol 2008;108:237244.

24 Inagaki Y, Yasui K, Endo M, Nakajima T, Zen K, Tsuji K, Minami M, Tanaka S, Taniwaki M, Itoh Y, Arii S, Okanoue T: CREB3L4, INTS3, and SNAPAP are targets for the 1q21 amplicon frequently detected in hepatocellular carcinoma. Cancer Genet Cytogenet 2008;180:30-36.

-25 Livak KJ, Schmittgen TD: Analysis of relative gene expression data using real-time quantitative PCR and the 2(-Delta Delta C(T)) Method. METHODS 2001;25:402-408.

26 Kim TH, Jo SH, Choi H, Park JM, Kim MY, Nojima H, Kim JW, Ahn YH: Identification of Creb3l4 as an essential negative regulator of adipogenesis. Cell Death Dis 2014;5:e1527.

-27 Javelaud D, Mauviel A: Mammalian transforming growth factor-betas: Smad signaling and physiopathological roles. Int J Biochem Cell Biol 2004;36:1161-1165.

28 Kang YS, Li Y, Dai C, Kiss LP, Wu C, Liu Y: Inhibition of integrin-linked kinase blocks podocyte epithelial-mesenchymal transition and ameliorates proteinuria. Kidney Int 2010;78:363-373.

29 Yang J, Liu Y: Dissection of key events in tubular epithelial to myofibroblast transition and its implications in renal interstitial fibrosis. Am J Pathol 2001;159:1465-1475. 


\section{Cellular Physiology Cell Physiol Biochem 2017;42:697-712 \begin{tabular}{ll|l} 
and Biochemistry & $\begin{array}{l}\text { Dublished online: June 13, } 2017 \\
\text { Publish } 2017 \text { The Author(s). Published by S. Karger AG, Basel } \\
\text { www.karger.com/cpb }\end{array}$ \\
\hline
\end{tabular} \\ Xiao et al.: Tisp40 in Renal Tubulointerstitial Fibrosis}

-30 Veerasamy M, Nguyen TQ, Motazed R, Pearson AL, Goldschmeding R, Dockrell ME: Differential regulation of E-cadherin and alpha-smooth muscle actin by BMP 7 in human renal proximal tubule epithelial cells and its implication in renal fibrosis. Am J Physiol Renal Physiol 2009;297:F1238-F1248.

-31 Eleveld-Trancikova D, Sanecka A, van Hout-Kuijer MA, Looman MW, Hendriks IA, Jansen BJ, Adema GJ: DC-STAMP interacts with ER-resident transcription factor LUMAN which becomes activated during DC maturation. Mol Immunol 2010;47:1963-1973.

-32 Gregorieff A, Stange DE, Kujala P, Begthel H, van den Born M, Korving J, Peters PJ, Clevers H: The etsdomain transcription factor Spdef promotes maturation of goblet and paneth cells in the intestinal epithelium. Gastroenterology 2009;137:1333-1345.

-33 Yamaguchi A, Hori O, Stern DM, Hartmann E, Ogawa S, Tohyama M: Stress-associated endoplasmic reticulum protein 1 (SERP1)/Ribosome-associated membrane protein 4 (RAMP4) stabilizes membrane proteins during stress and facilitates subsequent glycosylation. J Cell Biol 1999;147:11951204.

-34 Flier SN, Tanjore H, Kokkotou EG, Sugimoto H, Zeisberg M, Kalluri R: Identification of epithelial to mesenchymal transition as a novel source of fibroblasts in intestinal fibrosis. J Biol Chem 2010;285:20202-20212.

-35 Lecuit T, Yap AS: E-cadherin junctions as active mechanical integrators in tissue dynamics. Nat Cell Biol 2015;17:533-539.

-36 Ding L, Zhang Z, Shang D, Cheng J, Yuan H, Wu Y, Song X, Jiang H: Alpha-Smooth muscle actin-positive myofibroblasts, in association with epithelial-mesenchymal transition and lymphogenesis, is a critical prognostic parameter in patients with oral tongue squamous cell carcinoma. J Oral Pathol Med 2014;43:335-343.

-37 Chen KH, Hung CC, Hsu HH, Jing YH, Yang CW, Chen JK: Resveratrol ameliorates early diabetic nephropathy associated with suppression of augmented TGF-beta/smad and ERK1/2 signaling in streptozotocin-induced diabetic rats. Chem Biol Interact 2011;190:45-53.

- 38 Shen N, Lin H, Wu T, Wang D, Wang W, Xie H, Zhang J, Feng Z: Inhibition of TGF-beta1-receptor posttranslational core fucosylation attenuates rat renal interstitial fibrosis. Kidney Int 2013;84:6477.

39 Massague J: TGF-beta signal transduction. Annu Rev Biochem 1998;67:753-791.

-40 Cutroneo KR: TGF-beta-induced fibrosis and SMAD signaling: Oligo decoys as natural therapeutics for inhibition of tissue fibrosis and scarring. Wound Repair REGEN 2007;15:S54-S60.

41 Border WA, Noble NA: Evidence that TGF-beta should be a therapeutic target in diabetic nephropathy. Kidney Int 1998;54:1390-1391.

42 Moon JA, Kim HT, Cho IS, Sheen YY, Kim DK: IN-1130, a novel transforming growth factor-beta type I receptor kinase (ALK5) inhibitor, suppresses renal fibrosis in obstructive nephropathy. Kidney Int 2006;70:1234-1243.

43 Petersen M, Thorikay M, Deckers M, van Dinther M, Grygielko ET, Gellibert F, de Gouville AC, Huet S, Ten DP, Laping NJ: Oral administration of GW788388, an inhibitor of TGF-beta type I and II receptor kinases, decreases renal fibrosis. Kidney Int 2008;73:705-715.

-44 Cano A, Perez-Moreno MA, Rodrigo I, Locascio A, Blanco MJ, Del BM, Portillo F, Nieto MA: The transcription factor snail controls epithelial-mesenchymal transitions by repressing E-cadherin expression. Nat Cell Biol 2000;2:76-83.

45 Yoshino J, Monkawa T, Tsuji M, Inukai M, Itoh H, Hayashi M: Snail1 is involved in the renal epithelialmesenchymal transition. Biochem Biophys Res Commun 2007;362:63-68.

-46 Javelaud D, Mauviel A: Crosstalk mechanisms between the mitogen-activated protein kinase pathways and Smad signaling downstream of TGF-beta: Implications for carcinogenesis. Oncogene 2005;24:5742-5750.

47 Mori S, Matsuzaki K, Yoshida K, Furukawa F, Tahashi Y, Yamagata H, Sekimoto G, Seki T, Matsui H, Nishizawa M, Fujisawa J, Okazaki K: TGF-beta and HGF transmit the signals through JNK-dependent Smad2/3 phosphorylation at the linker regions. Oncogene 2004;23:7416-7429.

-48 Ding W, Wang B, Zhang M, Gu Y: Tempol, a superoxide Dismutase-Mimetic drug, ameliorates progression of renal disease in CKD mice. Cell Physiol Biochem 2015;36:2170-2182. 